LIVER

\title{
Bone marrow engraftment in a rodent model of chemical carcinogenesis but no role in the histogenesis of hepatocellular carcinoma
}

\author{
H Ishikawa, K Nakao, K Matsumoto, D Nishimura, T Ichikawa, K Hamasaki, K Eguchi
}

Gut 2004;53:884-889. doi: 10.1136/gut.2003.026047

See end of article for authors' affiliations

.....................

Correspondence to: Professor K Eguchi, The First Department of Internal Medicine, Nagasaki University of Medicine, 1-7-1 Sakamoto, Nagasaki, 852-8501, Japan; jaco@ venus.dti.ne.jp

Accepted for publication 14 December 2003

\begin{abstract}
Background and aim: Recent studies indicated that hepatic stem cells in the bone marrow could differentiate into mature hepatocytes, suggesting that bone marrow cells could be used for replacement of damaged hepatocytes in a variety of liver diseases. Hepatocellular carcinoma (HCC) is thought to arise from hepatic stem cells. In this study, we investigated the malignant potential of hepatic stem cells derived from the bone marrow in a mouse model of chemical hepatocarcinogenesis.

Methods: Bone marrow cells were obtained from the male $\beta$-galactosidase ( $\beta$-gal) transgenic mouse and transplanted into female recipient mice. Hepatocarcinogenesis was induced by a year of treatment with diethylnitrosamine and phenobarbital (NDEA/PB). One year later, the liver was removed from each treated mouse and evaluated by x-gal staining, immunohistochemistry, and fluorescence in situ hybridisation (FISH).

Results: Forty per cent of recipient mice survived and developed multiple HCC. Clusters of $\beta$-gal positive mature hepatocytes were detected sporadically in the entire liver of NDEA/PB treated mice who underwent bone marrow transplantation (BMT) with while no such hepatocytes were identified in the liver of BMT mice that were not treated with NDEA/PB. The $Y$ chromosome was detected with the same frequency as the donor male liver in clusters of $\beta$-gal positive mature hepatocytes by FISH. However, no HCC was positive for $\beta$-gal or the $Y$ chromosome. Immunohistochemically, $\beta$-gal positive mature hepatocytes did not express CD34 or $\alpha$-fetoprotein.

Conclusions: Our results suggest that hepatic stem cells derived from the bone marrow have low malignant potential, at least in our model.
\end{abstract}

A lthough patients at high risk of hepatocellular carcinoma (HCC) are well defined in the clinical setting, the process of hepatocarcinogenesis is not well understood. ${ }^{12}$ Hepatitis B or C virus can induce chronic hepatitis and potentially results in liver cirrhosis and HCC, and patients with these viral infections are the most frequent among HCC patients. ${ }^{3}$ However, the consequences of viral infection in the process of hepatocarcinogenesis are not clearly understood. In this regard, the original cell that develops into a cancerous cell in HCC is debated. ${ }^{4}$ Two cell lineages have been considered as candidates: the first is the hepatic stem cell and the second is the mature hepatocyte. However, there is no clear evidence on which cell is directly involved in the development of HCC. ${ }^{5} 6$

Extensive studies have been conducted on the hepatic stem cell but the results are controversial. Several candidate hepatic stem cells have been described in a rodent experimental model (including oval cells, liver epithelial cells, and small hepatocytes)..$^{-9}$ Previous studies indicated that bone marrow cells can differentiate into oval cells in rodents and that a similar process could possibly take place in humans..$^{10-12}$ If this scenario is correct, isolation of hepatic stem cells from bone marrow cells could be a valuable strategy for future replacement therapy of damaged or malfunctioned hapatocytes. ${ }^{10}$ However, the safety and efficacy of hepatic stem cells derived from bone marrow cells should be adequately confirmed before any such therapies are tested in humans.

In an attempt to assess hepatic stem cells, in the present study we investigated the malignant potential of hepatic stem cells derived from bone marrow in vivo. To identify hepatic stem cells, bone marrow cells of $\beta$-galactosidase ( $\beta$-gal) transgenic male mice were transplanted into recipient female mice. After bone marrow transplantation (BMT), HCC was induced in the recipients by chemical hepatocarcinogenic compounds and the presence of $\beta$-gal and the $\mathrm{Y}$ chromosome were evaluated in HCC.

\section{MATERIALS AND METHODS \\ Bone marrow transplantation}

Six week old male B6-129S-Gtrosa and female B6-129-F2 mice were purchased from Jackson Laboratory (Bar Habor, Maine, USA). B6-129S-Gtrosa mice express transgenic $\beta$-gal in the whole body and B6-129-F2 mice are the parental strain of B6-129S-Gtrosa. ${ }^{13}$ Animal experiments were performed in accordance with institutional guidelines, and the study was approved by the ethics committee of Nagasaki University. BMT was performed as reported previously. ${ }^{14}$ Briefly, the thigh was removed from a dead male B6-129S-Gtrosa, and bone marrow cells were harvested and suspended in phosphate buffered saline at a density of $1 \times 10^{7}$ cells $/ \mathrm{ml}$. Female B6-129-F2 mice were irradiated sublethally and $5 \times 10^{6}$ of the above bone marrow cells were injected via the tail vein. To confirm successful transplantation of donor bone marrow cells, a sample of recipient bone marrow cells was obtained from B6-129-F2 mice after sacrifice and examined for $\mathrm{x}$-gal staining.

Abbreviations: AFP, $\alpha$-fetoprotein; $\beta$-gal, $\beta$-galactosidase; BMT, bone marrow transplantation; FISH, fluorescence in situ hybridisation; $\mathrm{HCC}$, hepatocellular carcinoma; NDEA/PB, diethylnitrosamine/phenobarbital; $\mathrm{H} \& \mathrm{E}$, haematoxylin-eosin 

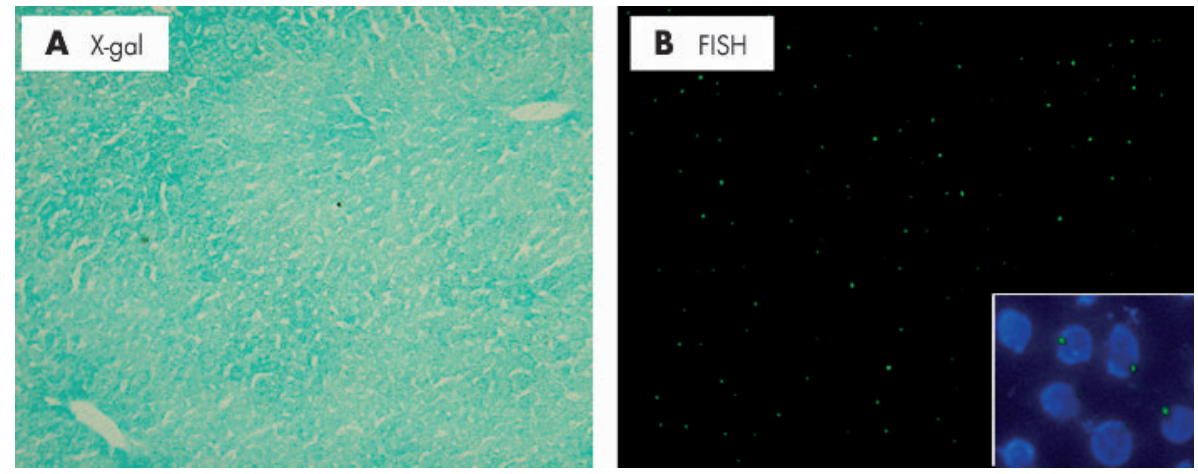

Figure $1 \mathrm{X}$-gal staining and fluorescence in situ hybridisation (FISH) for the $\mathrm{Y}$ chromosome in the liver of the donor mouse. To confirm expression of $\beta$-galactosidase and status of the $Y$ chromosome in donor mouse, $x$-gal staining and FISH were performed. (A) X-gal staining (magnification $\times 100$ ). (B) FISH for the Y chromosome (magnification $\times 100$ ). Inset; high magnification of FISH with counterstaining by DAPI (magnification $\times 400)$.

\section{Chemically induced hepatocarcinogenesis}

To induce HCC, two weeks after BMT, $80 \mathrm{mg} / \mathrm{l}$ diethylnitrosamine (NDEA; Sigma, St Louis, Missouri, USA) was added to the drinking water of B6-129-F2 recipient mice for six weeks to initiate the process of hepatocarcinogenesis. This was followed by administration of $700 \mathrm{mg} / \mathrm{l}$ phenobarbital (PB; Wako, Tokyo, Japan) as a tumour promoting agent, until sacrifice. Ten bone marrow transplanted and 10 nontransplanted mice were each treated with NDEA/PB, and four mice who underwent BMT but not NDEA/PB treatment and four mice who received no treatment were maintained under the same conditions as controls.

\section{$X$-gal staining}

One year after the start of NDEA, mice who survived were sacrificed and the liver and bone marrow harvested. The liver was fixed in $10 \%$ formalin for 24 hours and paraffin embedded. Simultaneously, fresh frozen sections were also prepared. Routine histology was performed with haematoxylin-eosin (H\&E) staining of both formalin fixed/paraffin embedded and fresh frozen sections. To identify bone marrow derived cells in the liver specimens, every fifth slide of $5 \mu \mathrm{m}$ thick serial sections (total 125 slides) was stained for X-gal. X-gal staining kit (Gene Therapy Systems, San Diego, California, USA) was used with fresh frozen sections of the liver removed from each group according to the instructions provided by the manufacturer.

\section{Immunohistochemistry}

Immunohistochemistry was performed using antimouse CD34 or antimouse $\alpha$-fetoprotein (AFP) antibody as the primary antibody. Tissue samples of the fresh frozen liver sections were cut into $5 \mu \mathrm{m}$ thick sections and mounted on aminopropyltriethoxysilane coated glass slides. The streptavidin-biotin method (Histofine Staining Kit; Nichirei Company, Tokyo, Japan) was used for immunohistochemical detection, as described previously. ${ }^{15} \mathrm{X}$-gal and immunohistochemically treated slides were counterstained with haema-

Table 1 Survival rate and success of BMT

\begin{tabular}{lcc}
\hline Treatment & Survival (n) & $\begin{array}{l}\boldsymbol{\beta} \text {-gal positive/negative } \\
\text { bone marrow cells }\end{array}$ \\
\hline (1) $\mathrm{BMT}(-), \mathrm{NDEA} / \mathrm{PB}(-)$ & $100 \%(4 / 4)$ & $0 \%$ \\
(2) $\mathrm{BMT}(+), \mathrm{NDEA} / \mathrm{PB}(-)$ & $100 \%(4 / 4)$ & $95 \%$ \\
(3) $\mathrm{BMT}(-), \mathrm{NDEA} / \mathrm{PB}(+)$ & $50 \%(5 / 10)$ & $0 \%$ \\
(4) $\mathrm{BMT}(+), \mathrm{NDEA} / \mathrm{PB}(+)$ & $40 \%(4 / 10)$ & $91 \%$ \\
\hline
\end{tabular}

BMT, bone marrow transplantation, NDEA, diethylnitrosamine, $\mathrm{PB}$, phenobarbital; $\beta$-gal, $\beta$-galactosidase. toxylin. Numbers of clusters or cells positively stained in each section were counted and mean (SD) values were calculated for each sample.

\section{Fluorescence in situ hybridisation}

Because BMT was performed from male donor mice to female recipient mice, the transplanted bone marrow derived cells could be recognised in the recipient by the presence of the $\mathrm{Y}$ chromosome in the nucleus. Therefore, fluorescence in situ hybridisation (FISH) for the mouse Y chromosome was conducted to detect the transplanted bone marrow derived cells. Liver specimens of fresh frozen sections were pretreated using the Pretreatment Reagent Kit (Vysis, Downers Grove, Illinois, USA) according to the instructions supplied by the manufacturer, and hybridised with a mouse Y chromosome probe (Cambio, Cambridge, UK). Treated slides were observed under fluorescent microscopy.

\section{RESULTS}

\section{$X$-gal staining and FISH of donor mice}

In this study, we used the male B6-129S-Gtrosa mouse as a donor. It has been reported previously that this mouse expresses $\beta$-gal throughout the whole body. ${ }^{13}$ To confirm this, we performed $\mathrm{x}$-gal staining and FISH for the $\mathrm{Y}$ chromosome in the liver. All hepatocytes were positive for $\mathrm{x}$-gal staining (fig lA) and $98 \%$ of bone marrow cells were x-gal stained (data not shown). FISH revealed that $28 \%$ of hepatocyte nuclei were positive for the Y chromosome (fig 1B). A positive FISH signal was detected in the nucleus which was confirmed by counterstaining with DAPI (fig 1B, inset). In addition, no nucleus showed two or more signals.

\section{Survival rate}

We first evaluated the survival rate of mice that underwent BMT and/or NDEA/PB treatment (table 1). All (100\%, 4/4 each) control mice and mice that underwent BMT only were still alive at the end of the study. However, only five of 10 $(50 \%)$ mice in the NDEA/PB treated group that did not undergo BMT were still alive at the end of the one year study period. The survival rate of mice subjected to BMT and NDEA/PB treatment was the lowest (4/10 mice, $40 \%$ ).

\section{Bone marrow transplantation}

To confirm bone marrow replacement with $\beta$-gal gene transduced cells, bone marrow cells derived from each group of recipient mice were subjected to $\mathrm{x}$-gal staining (fig $2 \mathrm{~A}, 2 \mathrm{~B}$ ). Red blood cells were excluded by careful microscopic observation and only nuclear cells were examined. No x-gal stained bone marrow nuclear cells were found in mice that did not receive BMT. In contrast, $91-95 \%$ of bone marrow 

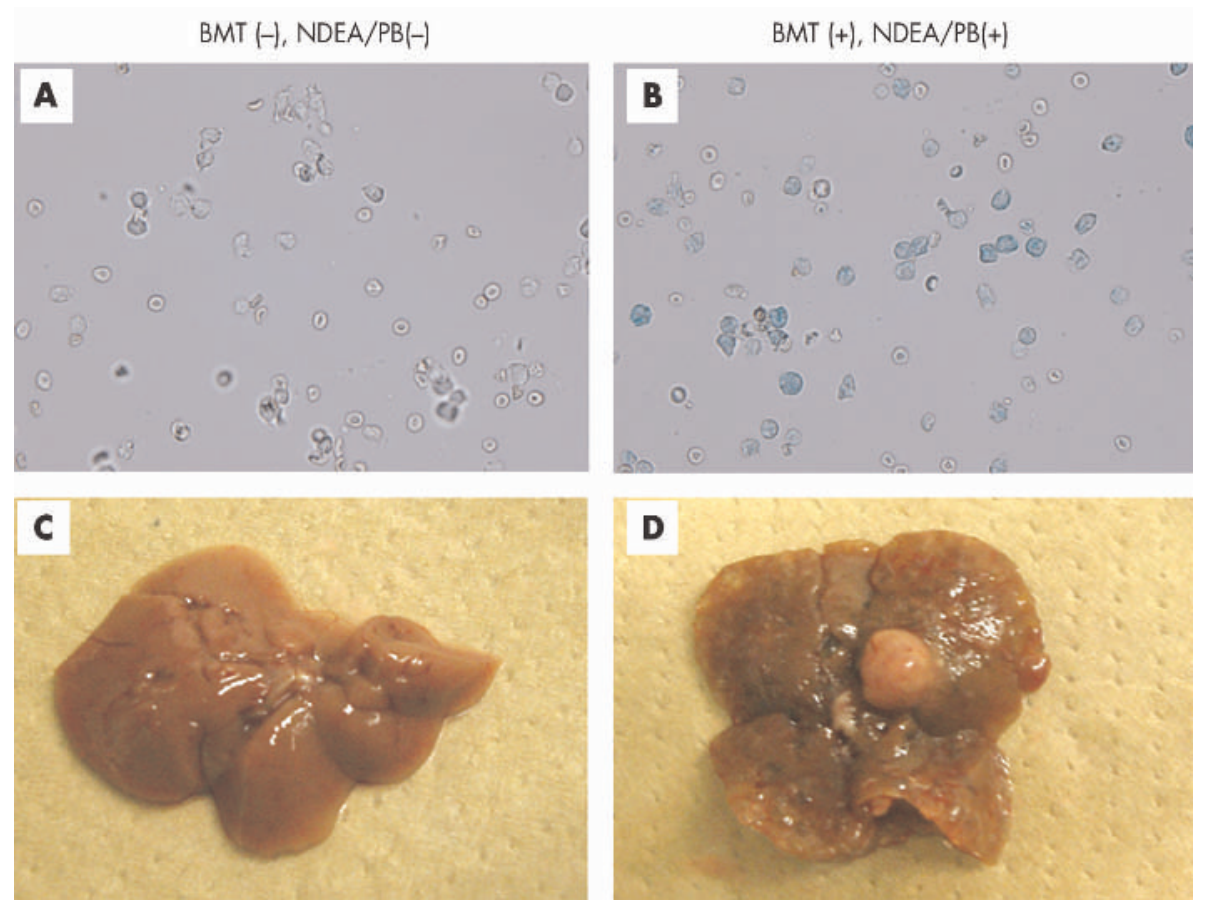

Figure 2 X-gal staining of bone marrow cells and hepatocellular carcinoma development in mice that underwent bone marrow transplantation (BMT) and diethylnitrosamine/phenobarbital (NDEA/PB) treatment. One year after the start of treatment, bone marrow cells were removed from each mouse and stained with $\mathrm{x}$-gal. $\beta$-Gal positive cells appear as blue stained cells. Representative photographs are shown. (A) Bone marrow cells derived from a non-treated control mouse. (B) BMT and NDEA/PB treated mouse. (C) The liver removed from a non-treated control mouse. (D) BMT and NDEA/PB treated mice (magnification $A$ and $B, \times 200)$.

cells were $\mathrm{x}$-gal stained in mice that received BMT with or without NDEA/PB treatment (table 1). These results indicated successful BMT in this study.

\section{Histopathological analysis of the liver of recipient mice}

NDEA/PB treatment resulted in the appearance of multiple macroscopic tumours in the liver after one year of treatment in both BMT and non-BMT mice (fig 2C, 2D). H\&E stained sections of these tumours confirmed they were HCC (see fig 6A), based on the criteria defined previously. ${ }^{16}$ No other types of liver tumours, such as hepatoblastoma or cholangiocellular carcinoma, were noted in our experiment. Apart from HCC, abundant denatured hepatocytes, oval cells, cysts, and bile duct proliferation were observed in NDEA/PB treated mice compared with control livers.

\section{Phenotypic analysis by $x$-gal staining, immunohistochemistry, and FISH}

In a preliminary study, we sacrificed two BMT mice and liver samples were removed before NDEA/PB treatment. In these samples, $\beta$-gal positive hepatocytes were not identified (data not shown). Furthermore, no $\beta$-gal positive mature hepatocytes were detected in the livers of BMT mice that were not treated with NDEA/PB one year after BMT except for hematic cells in blood vessels (fig 3). However, x-gal staining of fresh frozen liver samples of four BMT mice treated with NDEA/PB showed sporadic clusters of $\beta$-gal positive mature hepatocytes (fig 4A, 4B). The number of these clusters in four mice was mean 0.18 (SD 0.10) in $53(15) \mathrm{mm}^{2}$ sections $(0.34(0.10)$ cluster/ $\mathrm{cm}^{2}, \mathrm{n}=125$ slides). Furthermore, 17 (4.2) hepatocytes were present within the diameter of a cluster. Immunohistochemical analysis showed that $\beta$-gal positive
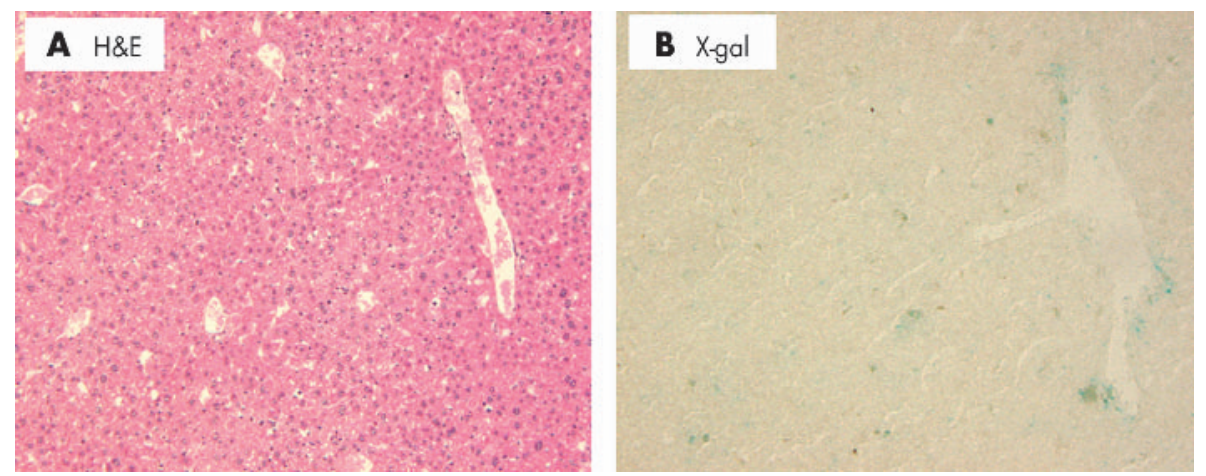

Figure 3 Haematoxylin-eosin (H\&E) and $x$-gal stained liver section obtained from a mouse who underwent bone marrow transplantation (BMT) but not diethylnitrosamine/phenobarbital treatment. One year after BMT, the mouse was sacrificed and the liver removed and stained, as described in materials and methods. (A) H\&E staining. (B) X-gal staining (magnification $\times 100$ ). 

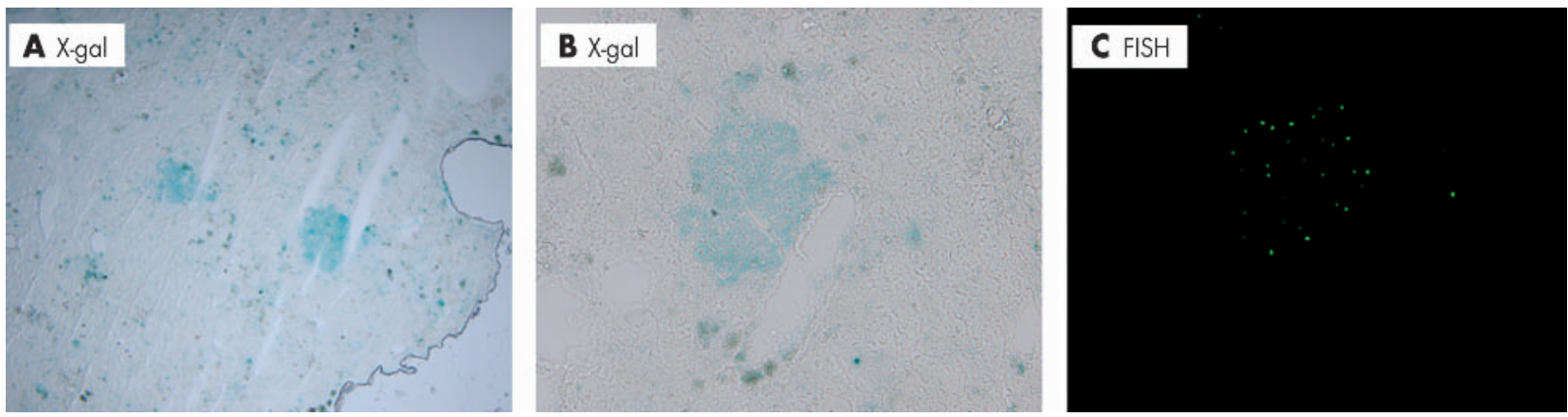

Figure 4 Appearance of $\beta$-galactosidase ( $\beta$-gal) positive cell clusters and confirmation of the $Y$ chromosome. (A) Numbers of $\beta$-gal positive cell clusters were counted in each $x$-gal stained slide examined under low magnification $(\times 40)$. (B) Representative photograph of $\beta$-gal positive cell cluster under high magnification $(\times 100)$. (C) Fluorescence in situ hybridisation (FISH) was performed as described in materials and methods to confirm the cell origin (magnification $\times 100$ ).

mature hepatocytes were negatively stained for CD34 and AFP (fig 5). In addition, FISH showed that $\beta$-gal positive mature hepatocytes were positive for the Y chromosome with the same frequency as the liver of donor male mice $(26 \%$, fig 4C). However, no HCC was positive for x-gal staining or FISH for the $\mathrm{Y}$ chromosome (fig $6, \mathrm{n}=10$ tumours).

\section{DISCUSSION}

The liver is classified as a conditionally renewing tissue and under normal circumstances nearly all hepatocytes proliferate quiescently, with only $0.3-0.5 \%$ of cell showing active cell division. ${ }^{17}$ Under normal physiological conditions, there is no need for hepatic stem cells, and they only become evident on demand (for example, in circumstances associated with severe hepatic liver damage and coexistent impaired hepatocyte division). Previous studies demonstrated that oval cells, which are considered hepatic stem cells, appear after chemically induced liver injury. ${ }^{18}$ Although the oval cell clearly appears in such conditions, its precise origin and existence under normal conditions remains unclear. Recent studies reported that bone marrow cells could differentiate into oval cells. ${ }^{12}{ }^{19}$ This finding indicates not only the origin of the oval cell but also the feasibility of in vivo labelling, at least in part, of oval cells.

In this study, we labelled bone marrow cells by $\beta$-gal staining. All hepatocytes were positive for $\beta$-gal in donor mice. Also, sensitivity of FISH for the Y chromosome was almost the same as that reported previously ${ }^{11}{ }^{12}$ while this sensitivity was inadequate for the detection of donor cells. Thus we believe that our methods for tracing bone marrow cells of donor mice were acceptable in the present study. After BMT, clusters of $\beta$-gal positive cells appeared only in BMT mice treated with NDEA/PB and not in BMT mice who did not receive NDEA/PB. These results suggest that in our
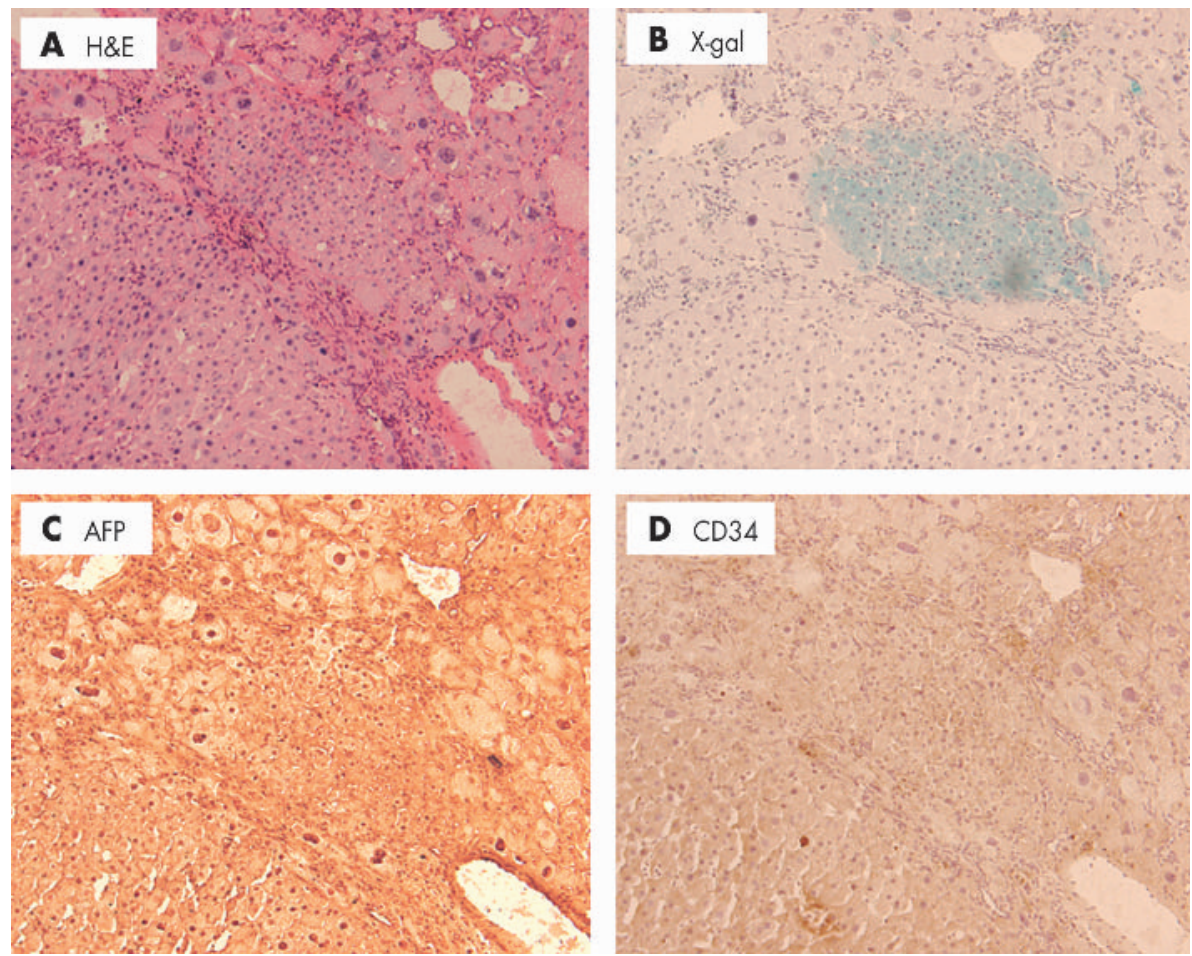

Figure 5 Immunohistochemical analysis of $\beta$-galactosidase ( $\beta$-gal) positive cell clusters in bone marrow transplantation and diethylnitrosamine/ phenobarbital treated mice. The phenotype of the $\beta$-gal positive cluster was determined by immunostaining. (A) Haematoxylin-eosin (H\&E) staining. (B) X-gal staining. (D) Immunostaining with antimouse CD34 antibody. (C) Antimouse $\alpha$-fetoprotein (AFP) (magnification $\times 100)$. 

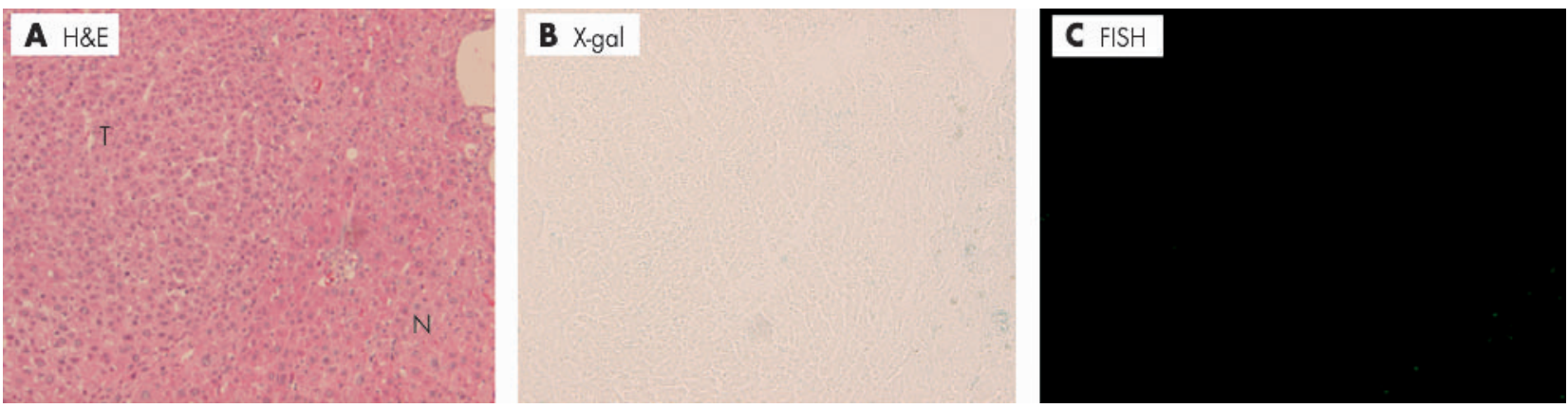

Figure 6 Histopathological analysis and x-gal staining of the tumour. Hepatocellular carcinoma (HCC) was induced by one year of treatment with diethylnitrosamine/phenobarbital (NDEA/PB), as described in materials and methods. Extracted livers were observed histopathologically under the microscope ( $\times 100)$. (A) Representative photograph of haematoxylin-eosin (H\&E) stained liver section obtained from a bone marrow transplantation and NDEA/PB treated mouse. T, HCC tumour; N, adjacent normal liver tissue. (B) X-gal staining of the serial section without any counterstaining. $\beta$-Galactosidase positive cells appear as blue stained cells $(\times 100)$. (C) Fluorescence in situ hybridisation (FISH) of the serial section (magnification $\times 100)$.

model, bone marrow cells can differentiate into mature hepatocytes under limited conditions. Bone marrow derived hepatic stem cells do not seem to be required for normal hepatocyte substitution. In addition, all hepatic stem cells derived from bone marrow cells may not have been labelled by this method and pre-existent hepatic stem cells, the origin of which is not clear, may be present in the liver. It has been reported that a stem cell of a particular tissue can differentiate into another tissue. ${ }^{20} 21$ A stem cell network may exist in the whole body and involve each other in variant tissues. Recently, some investigators have reported that cell fusion between a hepatic lineage cell and a bone marrow cell was the source of bone marrow derived hepatocytes in the $\mathrm{FAH}^{-1-}$ mouse model. ${ }^{22} 23$ However, other studies have shown that such fusion does not always play a role in haematopoietic to epithelial cell engraftment. ${ }^{24}$ Therefore, cell fusion may occur under specific conditions such as in the $\mathrm{FAH}^{-1-}$ mouse model. ${ }^{25}$ Indeed, in the present study, we found that in $\beta$-gal positive hepatocytes, no nucleus had two or more Y chromosomes by FISH. This finding indicates that transdifferentiation, rather than cell fusion, was the main process in our model.

In this study, our interest was focused on the original cell lineage of HCC. Two major hypotheses (the "stem cell theory" and the "hepatocytic theory") have been discussed for almost 20 years. ${ }^{626}{ }^{27}$ Debate has centred on whether hepatocytes in dysplastic nodules are responsible for HCCs through a process of dedifferentiation and proliferation, or whether oval cells are the prime targets for malignant changes after a differentiative "block", as proposed in some animal models. ${ }^{58}$ Possible involvement of oval cells in hepatocarcinogenesis is based on the following: (1) massive existence of oval cells in an animal rodent hepatocarcinogenic model ${ }^{29} ;$ (2) development of HCC after transformation of oval cells ${ }^{30} 31$; and (3) occurrence of mixed hepatocellular and cholangiocarcinomatous tumours (oval cell exhibits bipotential developmental ability). ${ }^{32}{ }^{33}$ However, the relationship between oval cells and cancer is only circumstantial. In this study, no HCC was positive for $\beta$-gal, and all $\beta$-gal positive cell clusters were oval cells or mature hepatocytes at the point of sacrifice, even after long term carcinogenic induction. These results allow exclusion of the stem cell theory and acceptance of the hepatocytic theory in hepatocarcinogenesis. However, as all hepatic stem cells might not have been labelled by our method, as mentioned above, we cannot completely exclude the stem cell theory. Although our results may be limited to BMT mice treated with NDEA/PB, we can state that the malignant potential of the hepatic stem cell derived from bone marrow seems to be low. Patients at high risk of HCC are clearly defined in the clinical settings, and viral hepatitis and/or related cirrhosis are the most critical factors. ${ }^{34}$ We selected the NDEA/PB model in the present study as it is a useful model of human hepatocarcinogenesis caused by viral hepatitis as nitrate and nitrosamine synthesis is increased in viral hepatitis. ${ }^{35}{ }^{36}$ Further studies are needed to clarify the precise interaction of bone marrow cells with hepatic regeneration and carcinogenesis using other animal models or human studies.

Liver transplantation has already been introduced for the treatment of patients with chronic or acute hepatic failure and congenital or malignant liver disease, and a large proportion of such patients have previously been reported to benefit from this procedure. ${ }^{37}$ However, there are some problems with liver transplantation, including shortage of donors. ${ }^{38}$ Cell based therapy is being developed for replacement of damaged or malfunctioned hepatocytes. ${ }^{39}$ Bone marrow cells may potentially be used in cell based replacement therapy or gene delivery systems. Under these circumstances, our results indicate that stem cell therapy is safe.

\section{ACKNOWLEDGMENTS}

We thank Drs Tomoya Nishino and Masanobu Miyazaki of the Second Department of Internal Medicine, Nagasaki University School of Medicine, for technical advice on BMT. We thank Tomomi Kurashige and Yoko Iwasaki for skilful technical assistance.

\section{Authors' affiliations}

H Ishikawa, K Matsumoto, D Nishimura, T Ichikawa, K Hamasaki, K Eguchi, The First Department of Internal Medicine, Nagasaki University School of Medicine, Nagasaki, Japan

K Nakao, Health Research Centre, Nagasaki University, Nagasaki, Japan

\section{REFERENCES}

1 Bergsland EK. Molecular mechanisms underlying the development of hepatocellular carcinoma. Semin Oncol 2001;28:521-31.

2 Schafer DF, Sorrell MF. Hepatocellular carcinoma. Lancet 1999:353:1253-7.

3 Hassan MM, Hwang LY, Hatten CJ, et al. Risk factors for hepatocellular carcinoma: synergism of alcohol with viral hepatitis and diabetes mellitus. Hepatology 2002;36:1206-13.

4 Sell S. Cellular origin of hepatocellular carcinomas. Semin Cell Dev Biol 2002; 13:419-24

5 Sell S. The role of determined stem-cells in the cellular lineage of hepatocellular carcinoma. Int J Dev Biol 1993;37:189-201.

6 Gournay J, Auvigne I, Pichard V, et al. In vivo cell lineage analysis during chemical hepatocarcinogenesis in rats using retroviral-mediated gene transfer: evidence for dedifferentiation of mature hepatocytes. Lab Invest 2002;82:781-8.

7 Forbes S, Vig P, Poulsom R, et al. Hepatic stem cells. J Pathol 2002;197:510-18. 
8 Mitaka T. Hepatic stem cells: from bone marrow cells to hepatocytes. Biochem Biophys Res Commun $2001 ; 281: 1-5$.

9 Thorgeirsson SS. Hepatic stem cells in liver regeneration. FASEB $J$ $1996 ; 10: 1249-56$.

10 Lagasse $\mathrm{E}$, Connors $\mathrm{H}$, Al-Dhalimy $\mathrm{M}$, et al. Purified hematopoietic stem cells can differentiate into hepatocytes in vivo. Nat Med 2000;6:1229-34.

11 Theise ND, Nimmakayalu M, Gardner R, et al. Liver from bone marrow in humans. Hepatology 2000;32:11-16.

12 Petersen BE, Bowen WC, Patrene KD, et al. Bone marrow as a potential source of hepatic oval cells. Science 1999;284:1168-70.

13 Friedrich G, Soriano P. Promoter traps in embryonic stem cells: a genetic screen to identify and mutate developmental genes in mice. Genes Dev 1991;5:1513-23.

14 Tsukada N, Kobata T, Aizawa Y, et al. Graft-versus-leukemia effect and graftversus-host disease can be differentiated by cytotoxic mechanisms in a murine model of allogeneic bone marrow transplantation. Blood 1999;93:2738-47.

15 Yamasaki S, Kawakami A, Nakashima T, et al. Importance of NF-kappaB in rheumatoid synovial tissues: in situ NF-kappaB expression and in vitro study using cultured synovial cells. Ann Rheum Dis 2001;60:678-84.

16 Ward JM. Morphology of hepatocellular neoplasms in B6C3F1 mice. Cancer Lett 1980;9:319-25.

17 Vessey CJ, Hall PM. Hepatic stem cells: a review. Pathology 2001;33:130-41.

18 Lazaro CA, Rhim JA, Yamada Y, et al. Generation of hepatocytes from oval cell precursors in culture. Cancer Res 1998;58:5514-22.

19 Theise ND, Badve S, Saxena R, et al. Derivation of hepatocytes from bone marrow cells in mice after radiation-induced myeloablation. Hepatology 2000;31:235-40.

20 Malouf NN, Coleman WB, Grisham JW, et al. Adult-derived stem cells from the liver become myocytes in the heart in vivo. Am J Pathol 2001;158:1929-35.

21 Clarke DL, Johansson CB, Wilbertz J, et al. Generalized potential of adult neural stem cells. Science 2000;288:1660-3.

22 Wang $X$, Willenbring $H$, Akkari $Y$, et al. Cell fusion is the principal source of bone-marrow-derived hepatocytes. Nature 2003;422:897-901.

23 Vassilopoulos G, Wang PR, Russell DW. Transplanted bone marrow regenerates liver by cell fusion. Nature 2003:422:901-4.

24 Newsome PN, Johannessen I, Boyle S, et al. Human cord blood-derived cells can differentiate into hepatocytes in the mouse liver with no evidence of cellular fusion. Gastroenterology 2003;124:1891-900.
25 Theise ND. Liver stem cells: the fall and rise of tissue biology. Hepatology 2003;38:804-6

26 Sell S, Dunsford HA. Evidence for the stem cell origin of hepatocellular carcinoma and cholangiocarcinoma. Am J Pathol 1989;134:1347-63.

27 Aterman K. The stem cells of the liver-a selective review. J Cancer Res Clin Oncol 1992;118:87-115.

28 Potter VR. Phenotypic diversity in experimental hepatomas: the concept of partially blocked ontogeny. The 10th Walter Hubert Lecture. Br J Cancer 1978;38:1-23.

29 Anilkumar TV, Golding M, Edwards RJ, et al. The resistant hepatocyte model of carcinogenesis in the rat: the apparent independent development of oval cell proliferation and early nodules. Carcinogenesis 1995;16:845-53.

30 Braun L, Mikumo R, Fausto N. Production of hepatocellular carcinoma by oval cells: cell cycle expression of c-myc and p53 at different stages of oval cell transformation. Cancer Res 1989;49:1554-61.

31 Dumble ML, Croager EJ, Yeoh GC, et al. Generation and characterization of p53 null transformed hepatic progenitor cells: oval cells give rise to hepatocellular carcinoma. Carcinogenesis 2002;23:435-45.

32 Goodman ZD, Ishak KG, Langloss JM, et al. Combined hepatocellularcholangiocarcinoma. A histologic and immunohistochemical study. Cancer 1985; 55: 124-35.

33 Tsao MS, Grisham JW. Hepatocarcinomas, cholangiocarcinomas, and hepatoblastomas produced by chemically transformed cultured rat liver epithelial cells. A light- and electron-microscopic analysis. Am J Pathol 1987; 127:168-81.

34 Chen CJ, Chen DS. Interaction of hepatitis B virus, chemical carcinogen, and genetic susceptibility: multistage hepatocarcinogenesis with multifactorial etiology. Hepatology 2002;36:1046-9.

35 Liu RH, Baldwin B, Tennant BC, et al. Elevated formation of nitrate and Nnitrosodimethylamine in woodchucks (Marmota monax) associated with chronic woodchuck hepatitis virus infection. Cancer Res 1991;51:3925-9.

36 Liv RH, Jacob JR, Tennant BC, et al. Nitrite and nitrosamine synthesis by hepatocytes isolated from normal woodchucks (Marmota monax) and woodchucks chronically infected with woodchuck hepatitis virus. Cancer Res 1992;52:4139-43.

37 Hemming AW, Nelson DR, Reed Al. Liver transplantation for hepatocellular carcinoma. Minerva Chir 2002:57:575-85.

38 Neuberger J. Liver transplantation. J Hepatol 2000;1:198-207.

39 Ohashi K, Park F, Kay MA. Hepatocyte transplantation: clinical and experimental application. J Mol Med $2001 ; 79: 617-30$. 